\section{REMARKS OF A CASE OF SPASMODIC ENGLISH CHOLERA.}

Bx W. M. FAIRBRoTHER, Esq., M.R.C.S.E.

Mx attendance was required, on the evening of July the 8th, by a female about fifty years of age, residing near St. George'sroad. She had been attacked soon after dinner with vomiting and purging, the motions at first denoting the presence of bile, but after the second, its total suppression. Her sharpened featnres expressed the most extreme pain, and the few words which she spoke were uttered in a shrill, whining manner. The urine was almost suppressed; the pulse small and weak. She was ordered to take immediately a pill, with six grains of calomel and a full dose of opium, (being accustomed to the daily use of that drug, and a chalk mixture in an aromatic form. On calling in an hour's time, the patient was much worse. The extremities were cold; the pulse was imperceptible at the wrist, and the carotids could only be occasionally felt; the vox cholerica was more marked; the cramp increased, and she could with difficulty be kept in bed. Sinapisms were applied very freely to the feet and legs, abdomen, and over the heart, also to the cervical portion of the spine. Brandy, in doses of two ounces, was administered at intervals. Her speech was now entirely lost, the face and body were of a faint blue tint, and the vomiting continued, but. to a less degree. In two hours, during which time fresh mustard was several times applied, friction being employed at the same time, some signs of re-action appeared, and the radial artery could be faintly felt. Ordered to take four grains of calomel with-opium every two hours, and a mixture of ether and ammonia; to continue the brandy in smaller quantities. On my next visit there was some amendment, and the following day, symptoms of intestinal inflammation, which yielded to appropriate treatment. The motions became bilious after four doses of the calomel, and the urine was freely secreted.

Now I do not expect to see more violent cases than this, on the average, should the Asiatic scourge again visit us, unless called in to witness the patient in articulo mortis. This female lived within ten yards of a drain-stagnant, uncovered, and for many years a pest to the neighbourhood, and a hot-bed for fever. I would remark that the mere application of mustard as a poultice to a patient suffering from collapse in cholera is not so efficacious as friction with the same, cleanliness in its use being easily accomplished. The strongest counterirritation, and that which can be most quickly obtained, should be employed to unload the large mesenteric veins, and those of the abdominal viscera, in preference to venesection. Calomel in doses not too large must always be esteemed an invaluable remedy. Opium, not much to be recommended in the stage of collapse, is useful in the first and third stages. Brandy, ether, and ammonia, are valuable stimulants. The after complications of inflammation and fever may be treated on general grounds. It has been advised by Mr. Samuel Cooper to place a patient attacked with cholera in a heated room; this can be done in less time than a bath can be prepared, and would prove of service by inducing perspiration. Also this is a useful caution, that no case of diarrhcea should be suffered to persist unchocked during the prevalence of cholera.

London-road, July, $18 \$ 8$.

REPORT OF AN INSTANCE OF

ACUTE ILEUS, TREATED BY LARGE ABDOMINAL INCISION.

DEATH; REMARKS ON THE CASE.

BY J. A. GRAHAM, Ese., Surg., Basford, Nottinghamshire.

Os the 19th of July, Mr. Allen, of Arnold, was called in to visit A. R. T_— of Daybrook, who presented symptoms as follows:-Tongue white and moist; pulse 80, compressible abdomen tense, no particular pain on pressure; has not had any evacuation since the 1 th inst. TVas attacked on the evening of the 18th, after a dinner of peas, with pain and cramp in the umbilical region. This continuing during the night, he took a dose of castor oil; but having failed in procuring either an evacuation, or any relief, and the symrtom being increased in intensity, they called in Mr. Allen, who immediately attended, and prescribed an active calomel purge; twelve leeches to the abomen; warm fomentations, and large emollient enemata to be thrown up by $O^{\prime} B r i e n ' s ~ t u b e$.

20th.-Has passed a restless night, owing to constant retching; enemata had acted, bringing away some scybala, but he has not had any regular evacuation from the upper portion of the intestine, though a desire was experienced to obtain relief by straining; abdomen rather more tense, with slight fulness in right hypogastric region; tongue same; pulse 80 , irritable; countenance composed, but pale; sickness unabated. Repeat eeches, and apply a large blister to the abdomen; continue enemata. To be restricted from food of any kind, and only a small quantity of mint tea allowed to allay sickness, as almast everything was rejected.

21st.-No amendment; there has been a gradual aggravation of all the symptoms. A consultation being deemed advisable, Mr. J. Alfred Graham, of Basford, was called in. On visiting the patient, it was found, that in addition to his other symptoms, there were now superadded,-constant sickness, occasional singultus, slight tympanitis, and decided fulness in the right hypogastric region; pulse 90, of moderate power tongue white; countenance good; abdomen was full, but remarkably tolerant. Ordered to continue enemata, with repeated small doses of castor oil in mint water, every four hours; and a large linseed poultice to be applied to the abdomen; mint tea, with a little brandy, to be sipped at intervals, as this was found the only thing that could be tclerated by the stomach.

22 nd.- Not being able, owing to an engagement, to see the patient this morning, Mr. Allen visited alone. Symptoms unaltered. Mr. Allen administered, at two doses, a pound of quicksilver, without any good result.-Two P.M.: We visited the patient together, when we found stercoraceous vomiting as an additional symptom; abdomen still remarkably tolerant of pressure; tympanitis, with evidence of considerable fluid in intestines; pulse 95 ; tongue white and moist.-Three P.M.: Having explained the nature of his case to the patient and his friends, we mentioned, as a last resource, the expedient of an exploratory incision into the abdomen. The patient was urgent to have it performed, and at half-past three, all appliances being in readiness, we proceeded to the

Operation.-The patient having been placed on a table in a good light, I commenced by making a rapid incision through the integuments, from the border of the rib in the right hypochondrium, carried obliquely down to within half an inch of Poupart's ligament; then having cautiously cut through the muscles, fascia, and peritonæum, at the upper portion, and having introduced the index finger of the left hand so guided, I rapidly cut through all the parts to the extent of the external incision. There was scarcely any hæmorrhage. A ligature was placed on the epigastric artery. No fluid escaped on the peritonaum being opened. This incision, now fully expanded, displayed the intestines greatly distended with air and fluid, and of a darls plum colour, soft, and thickened, but without any traces of coagulable lymph, or localization of the inflammation to any viscus. The intestines did not immediately protrude themselves "en masse;" but as we proceeded, all that were free came completely out. We directed immediately our examination to the right iliac region, and found a knuckle of intestine adherent to the commencement of the ascending colon. On drawing it down so as to produce an acute angle, and on still following on the colon, it was found to have been drawn down to the side of the fundus of the bladder, where it was bound down and completely encircled by a ring of false membrane, so as almost to stop all passage. This band, which was directly divided, had evidently been of old formation, as its surface was polished, and its structure firm. Having then examined for any further cause of the symptoms, and finding none, we returned the intestines, after great difficulty, united the wound by the interrupted suture, and adhesive straps between, and applied a broad binder to support the whole. The patient placed in bed, had a dose of brandy, with tincture of opium. Ife had borne the operation remarkably well, and was cheerful; but after being placed in bed, constant stercoraceous vomiting ensued, and he gradually sank in four hours. A post-mortem was not permitted. The oniy assignable cause which the patient gave for the disease was, that when a child he had been severely scalded over the abdomen, and that ever since, he had, on any irregularity of diet, been subject to cramps.

Remarks.-Considering the fatal termination of this case, many persons might feel disposed to set down the means employed as a failure, and advance it as one in favour of not interfering by operation in cases requiring abdominal section. That an opening into the abdominal cavity, per se, is not necessarily, or even generally fatal, is now admitted on all hands, - the only valid objection to its performance being the difficulty of determining beforehand where we are to look for the cause of obstruction. In this case we had abundant evidence, and such as was conclusive in our opinions; and we should have no hesitation in again resorting; in a similar case, 
to the operation. Our only care would be to adopt it early, as we feel confident had it been performed before inflammation had proceeded so far, that the result would have been a recovery; just in the same manner that cases of strangulated hernia depend for recovery, not so much on this or that operator or operation, or on any of the treatments adopted, but on the circumstance of the operation being performed before inflammation shall have spread to the peritonæum and intestines.

Basford, Nottingham, July, 1548.

\section{Analnges}

\section{COMMUNICATIONS IN MS. RECEIVED FOR PUBLICATION IN THE LANCET.}

"L'auteur se tue à allonger ce que le lecteur se tue à abréger."

On Medical Corporation Reform.

By W. M. Fatrbrother, Esq., Surgeon, London-road.

"On reading, some time ago, a letter written on the above subject, by Dr. Dick, which appeared in ThE LANCET for April, I must confess that, at first, doubts arose in my mind, whether some racy satire was not intended by the author, which would be more clearly appreciated at the close of the letter. My surprise increased tenfold, when it appeared that the question of the entire abolition of all medical corporations was seriously intended to be advocated-it was, in fact, a startling novelty! That many abuses exist under the present system cannot be denied, and any proposition to remedy these would meet with the consideration its importance demanded; but when we have communism in medicine inculcated, some attempt at refutation seems desirable.

"The study of medicine is vast, to those who follow it as they ought. The mind at first attempting it requires some guidance and teaching; and this is best effected by those men who have patiently, for a great period of their lives, considered what precepts are worthy to be remembered, and what may be dispensed with. I hold that this cannot be more fairly accomplished than at our recognised medical schools. It cannot be tanght by books alone-but in the hospital, lecture, and dissecting rooms. It is most important, that some general standard of excellence should be obtained by all; and the higher that standard becomes, the safer is it for the public health.

"Your correspondent observes, that the fixed places, terms, and modes of study unwarrantably interfere with 'private and individual liberty of choice and action.' I cannot consider so, when the office of a medical man is of such high eharacter and of such vast importance. The three years of study are surely not too much for him who desires to perform his duties well in after life. His diplomas ought to be the guarantee to those who employ him, that their health is not entrusted to an uneducated man.

"Your correspondent remarks, that some might fear that the art would become extinct, were there no 'legal establishment of medicine.' With him, I think not, for there would always be some eminent men, lights to their profession, and ornaments to their country. But, on the other hand, hosts of noisy theorists, impudent quacks, and ignorant men, would so far undo what the examining bodies have accomplished within these last thirty years, that the old times would again return of misty theory and dangerous practice."

\section{Medical Registration and Reform.}

"Colmegran" addresses us as follows:-

"After the reception your Medical Registration Bill met with in the House of Commons, and the unanimous support given to it by the profession, and also the promises of the present Home Secretary, to render all his aid in carrying such a measure, $I$ expected, in common with the many thousands who fully coincided with the principles it set forth, that long ere this it would have become law. Yet, since the in troduction of your excellent Bill, (which contains all our wants and de. sires,) session after session has glided by, and alas! nothing is attained.

In referring to members of the Scotch and Irish medical institutions, and of the London College of Surgeons, he says, "It is most iniquitous that gentlemen of such acknowledged merit should be restricted in the exercise of any branch of the profession. It is properly remarked, in extracts in your journal, that 'to all purposes and in every way the surgeon is a physician, with the ability to operate chirurgically superadded to the medical acquirement; and he is conventionally to operate, prescribe, and receive his fee, as long as he calls himself "Surgeon." "I trust the legislature will at once unite us in one college, and cause the profession to be entered by one portal.

"In conclusion, Sir, allow me to say, that if petitions are necessary to assist you in your great work, say the word, and you will be inundated with them. We are ready to act, almost to a man, under your leadership; you will find us faithful and devoted to the good cause, which we have been much too long, and at great cost and injury, waiting for. May the time now be close at hand, when thousands shall gratefully congratulate you and themselves on success."

** We may remind our correspondent, that after the prolonged labours of the Medical Committee of the House of Commons, and the attention which has been given to the subject of medical organization by a portion of the legislature, a medical bill now brought into parliament ought to be of a much more comprehensive nature than one simply for medical registration.-ED. $L$.

\section{On Emigration, and the Advantages it presents to our} over-stocked Profession.

Dr. John Janes Macaregor, in a note to us, remarks, "The public as well as the medical profession feel indebted to you for the manner in which you have drawn their attention to the very important subject of emigration, and for giving additional publicity to the syllabus of government regulations, pnblished by the emigration agent, $\mathrm{Mr}$. Walcott.

"My object," he adds, "in addressing these few lines to you is chiefly to draw public attention, as well as that of the profession, to your admirable article on emigration, in THE LANCEN of the 24 th of June, on the medical appointments, as as well as cordially to respond to the views of the writer on medical emigration, which appear to me, at the present moment, peculiarly apposite and practical. It is beyond dispute, that in the British Islands our profession is utterly overdone, the number of medical men being out of all proportion to the population, and this despite the decimating blight of Irish typhus, as well as the moral miasmata generated by the mortal struggle after existence, especially in our crowded cities. What, then, can present a more natural and healthy safety-valve in such a human pressure than a prudent emigration to our colonies, where workmen, whether intellectual or physical, seem to be at the present moment in high demand ? I hope, Sir, you will dwell at more length on this most im portant topic, in your future numbers, and pause not before you enlist the attention of government towards holding out encouragement to well-qualified medical men to settle in our colonies. I trust, also, the profession will give the subject their serious consideration, numbers of whom, with talents and acquirements sufficient to entitle them to the highest distinc. tion, are scarcely able to procure the common decencies of life, and in order to 'keep up appearances' at home, are wasting their prime of existence in the vain and fruitless pursuit of an empty shadow, and, worse than all, losing their independence and self-respect in the frightful conflict. "Divide et impera,' although in a very different sense from that in which it is commonly applied, would seem, in our day, to be the most likely strategy to ensure the battle; and I have little doubt that hundreds, whose talents at home, owing to obstacles from enormous competition, are unknown or disregarded, would be justly estimated by their countrymen in a foreign land."

\section{ZRebíetos.}

Recent Advances in the Physiology of Motion, the Senses, Gener $\alpha_{-}$ tion, and Development. By WillraM BALY, M.D., F.R.S., \&c., and W. S. KInkes, M.D. Being a Supplement to the 2nd volume of Muller's "Elements of Physiology." London: Taylor and Walton. 1818. pp. 132.

MoLher's "Elements of Physiology" has enjoyed, ever since its publication in an English dress, the highest reputation amongst the published works on the subject, and it is now with much pleasure that we see it brought up to the present state of knowledge with respect to some of the more important 